\title{
How to Make Health and Risk Communication on Social Media More "Social" During COVID-19
}

\author{
Anat Gesser-Edelsburg (i) \\ School of Public Health and the Health \\ and Risk Communication Research \\ Center, University of Haifa, Haifa, \\ 3498838, Israel
}

\begin{abstract}
Social media have changed the way citizens participate in and express opinions about government policy. Social media serve organizations in achieving four main goals: interacting with citizens; fostering citizen participation; furthering open government; and analyzing/monitoring public opinion and activities. We contend that despite the importance of social media, international and local health organizations have been slow to adopt to them, primarily due to the discrepancy between intraorganizational discourse modes and the type of discourse suitable for dialogue with the public. In this perspective paper, we recommend strategies for such public dialogue based on understanding the challenges faced by organizations on the road to becoming more "social" in their social media presence and in their health and risk communication. Subsequently, we propose an integrative approach that combines three complementary paths: (1) putting the "social" back into health organizations' culture by inserting more "social" content into the internal organizational discourse through consultation with experts from different fields, including those who diverge from the scientific consensus. (2) Using strategies to enable health organizations to respond to the public on social networks, based on health communications research and studies on emerging infectious disease (EID) communication. (3) Engaging the public on social media based on the participatory approach, which considers the public as a partner that understands science and can work with the organizations to develop an open and innovative pandemic realm by using crowdsourcing to solve complex global health problems. For each path, we define the current challenges, among which are (1) overcoming organizational groupthink and hidden profiles, (2) treating all unofficial information as misleading, and (3) insufficient public engagement in solving complex global problems. We then offer recommendations for dealing with each challenge.
\end{abstract}

Keywords: health and risk communication, social media, emerging infectious disease communication, misinformation, infodemic, COVID-19

\section{Introduction}

\section{Background}

During my 20 years as a researcher, I have conducted extensive empirical research in the field of Emerging Infectious Diseases (EID) communication and health and risk communication. This research has included involvement in two EU Commission projects, TellMe ${ }^{1}$ and Asset, ${ }^{2}$ both encompasses studies of organizational communication in risk and health contexts. ${ }^{3-14}$

Controlled dissemination of information by governments and health authorities is no longer an option but rather a necessity. Yet, as the New York Times medical journalist Lawrence Altman has argued, "even though health officials have had
Correspondence: Anat Gesser-Edelsburg School of Public Health and the Health and Risk Communication Research Center, University of Haifa, 199 Aba Khoushy Ave., Mount Carmel, Haifa, 3498838, Israel

Tel +972544243530

Fax +97336322143

Email ageser@univ.haifa.ac.il 
ample time-years - to polish their language skills" and their practice, they still failed to communicate important health information in response to the Ebola epidemic in 2014, just as they failed during the HIV crisis in the 1980s. And thus, as Altman claimed, "history repeats itself". ${ }^{15}$

In a book I co-authored, titled Risk Communication and Infectious Diseases in an Age of Digital Media and published in 2016 by Routledge Studies in Public Health, ${ }^{11}$ we explored different organizational strategies for communicating public health information and identified common misconceptions while analyzing different studies. Yet an examination of the conduct of some of the health organizations in several countries during the COVID-19 crisis indicates that a significant portion of the approaches based on risk communications in general and on EID communication in particular regrettably were not implemented.

\section{Objective/Rationale}

This perspective paper seeks to sharpen some of the ideas that have emerged in research studies over the years and in my book on risk communication as well as to add additional ideas. The most important of these, as clarified in this paper, is the question of how to implement conceptual notions of risk communications so that they do not remain merely at the theoretical level. The paper discusses how government authorities can transform these theoretical notions into risk communication strategies and tactics that can be applied during a global pandemic crisis such as COVID-19 and other epidemiological crises as well. In addition, to the best of our knowledge this paper is the first to make a connection between the inner discourse within organizations and the way in which this discourse affects the strategies these health organizations adopt in communicating information and guidelines to the public. Most studies in the field of management or public relations focus on internal organizational management and discuss the impact of organizational culture on employee output and welfare. They do not discuss communication mechanisms or how these can be adapted to the field of health.

This perspective paper propose three complementary paths to help international and local health organizations use social media effectively. Closer examination shows that the way an organization manages its internal discourse affects the way it communicates on the various social media platforms. Effective dialogue with the public is based on transparent, open and diverse health and risk communication in the social media realm. ${ }^{16}$ An organization's social media campaigns can only include such features if these are already part of the organization's own communications culture. Information transparency begins inside the organization itself. The organization must recognize different voices and be capable of revealing these along with the decision-making process leading to a specific policy.

Through these three paths, the paper seeks to promote a democratic policy approach that can change how internal and external international and local organizational discourse is conducted in order to reduce the discrepancy between organizational intentions and practical applications in the field.

\section{What Does It Mean to Make Health Organizational Culture and Strategies More "Social"?}

Path 1 - Put More "Social" Content into Health Organizations' Culture: This path is based on organizational psychology and entails putting more "social" content into the internal organizational discourse by consulting experts from different fields, including those whose ideas diverge from those of the scientific consensus.

Path 2 - Strategies for Enabling Health Organizations to Respond on Social Networks: This path involves engaging in open and ongoing dialogue with the public that goes beyond the prevailing model of generic questions and answers.

Path 3 - Engage the Public on Social Media: This path entails using "more social" means of engaging the public and adapting organizational information to the concerns and needs of different population groups.

\section{Path I: Put More "Social" Content into Health Organizations' Culture}

How an organization manages its internal discourse influences how it communicates on social media platforms. Effective dialogue with the public is based on transparent, open and diverse health and risk communication, which can only be part of an organization's social media campaigns if they are also part of the organization's own communications culture. Indeed, information transparency begins when an organization recognizes different voices and is able to reveal the decision-making processes leading to a specific policy.

The paper discusses the following challenges and makes recommendations for managing each of them: (1) 
overcoming organizational groupthink and hidden profiles; (2) handling the tendency to place emphasis on scientific consensus while hiding disputes; (3) public health experts versus "people with agendas"; (4) conflicts of interest that interfere with decision-making, (5) the assumption that the public is overly emotional and irrational; and (6) diminished funding for risk communications experts.

\section{Engage in Professional and Intellectually Diverse Decision-Making Challenge: Overcoming Organizational Groupthink and Hidden Profiles}

Studies on decision-making ${ }^{17-19}$ and management strategy indicate that groups make more educated decisions than individuals and larger groups reach better decisions than smaller groups. Yet to achieve good performance, groups must overcome "groupthink". According to social psychologist Janis (1972), groupthink describes how ingroup pressures make group members strive for unanimity, causing decision-making to deteriorate and failing to appraise alternative courses of action. ${ }^{17}$ Previously the research consensus was that the more cohesive the group, the more effective its decisions. ${ }^{17}$ Janis, in contrast, found that group cohesiveness and blind trust can undermine group decisions. The paradox of groupthink is that unanimous decisions may appear to reflect resoluteness when in fact they result from individual members' attempts to avoid dissent. ${ }^{20}$

Janis contended that groups or organizations that strangle dissent in their decision-making fail to study alternatives and consequences, leading to fiascos such as the Watergate cover-up or Nazi Germany's invasion of the Soviet Union in 1941. ${ }^{17,21}$ Houghton (2008) stated that the Bush administration made many "errors" in embarking on a war in Iraq as a result of impulsive decision-making and groupthink. ${ }^{22}$ The Chilcot Inquiry (2016) made similar points about the decisions made by the UK government under Blair. $^{23}$

Leaders who take a centralist approach to management tend to avoid dissenting information or opinions and guide the organization to ignore such opinions when making decisions, ${ }^{24,25}$ leading to erroneous conclusions. When leaders provide only partial information in the form of "hidden profiles", ${ }^{26}$ the organization may make erroneous decisions. ${ }^{27}$

Health organization leadership, which in most cases avoids cognitive diversity and tends to ignore or hide profiles during a crisis, may make decisions that fail to consider the whole picture. This tendency may be reflected in the organization's social media campaigns: ignoring scientific disputes, choosing to communicate only one side of an issue, and conveying partial information to the public on social networks.

\section{Recommendation: Adopt Diverse Decision-Making Strategies}

Empirical studies that tested Janis's assumptions regarding groupthink did not reach any unequivocal conclusions about what predicts organizational failure. ${ }^{28,29}$ Yet most agreed that whether an organization addresses substantial disputes and conflicts has the greatest impact on effective decision-making. This point suggests that substantive diversity of opinions and conflict can be beneficial to decision-making.

Nevertheless, these studies also suggest that disputes and conflicts based on personal factors (eg, ego conflicts) are not helpful but rather are harmful to outcomes. Dissent can harm information elaboration if top managers do not make joint efforts to bring together various points of view and diverse pockets of information. ${ }^{24,25}$ Studies also indicate that management teams with more training and experiential diversity typically introduce more innovations. ${ }^{30}$ Informational diversity can stimulate creativity, innovation, and decision quality. ${ }^{31}$ Furthermore, the literature on decision-making and cognitive biases indicates that diverse teams may reduce biased judgments as they foster information-sharing and new perspectives. ${ }^{32}$

Public relations studies also stress the importance of extending the decision-making circle in organizations by engaging the employees. Specifically, the internal communications (IC) approach ${ }^{33}$ emphasizes the need for effective communications among participants within an organization that will influence how management decisions are perceived internally and externally. When the needs and thoughts of the entire spectrum of employees, from management to the lowest level workers, are taken into consideration, the employees' level of trust and commitment to the organization rises. The more engaged, committed and inspired an employee, the higher the employee's performance and the greater the impact on the bottom line. ${ }^{33}$

Furthermore, organizations increasingly see IC as playing a role in managing their external standing. In other words, the decision-making process and the employee's level of trust in the organization influence how the public 
perceives the organization, particularly in the age of social networks. $^{34,35}$

During the COVID-19 crisis, the Prime Minister of New Zealand earned praise for using diverse rather than selective information and presenting it transparently to the public. Moreover, the way in which she included her colleagues in the decision-making process had an impact on the visibility and status of her decisions. The Prime Minister introduced Facebook live chats to reach out to her constituency in an informal yet informative way. ${ }^{36,37} \mathrm{Her}$ "we're all in this together" attitude earned her the trust and support of the citizens, making it possible to enforce a Level 4 national lockdown. ${ }^{38}$

Cairney and Kwiatkowski ${ }^{39}$ emphasized the importance of engaging with real world policymaking rather than waiting for a "rational" and orderly process to emerge. To provide evidence during mythical stages of a policy cycle may be misguided, and to "speak truth to power" without establishing trust in networks and an open organizational culture may be counterproductive.

In light of the aforesaid, in most cases health organizations should adopt a decision-making approach that is open to diverse opinions and disputes and does not block discussion, especially during crises and when facing complex missions. Diverse decision-making also involves recruiting "outside the boardroom" professionals from various disciplines to serve on advisory boards. Such professionals should be consulted regularly, not only at times of crisis, to stimulate more meaningful discussions. Consultation with experts from different fields can also help organizations develop communication campaigns to address different aspects of the crisis (communication, social, healthcare) on social media. Campaigns that follow these recommendations will become more "social" (eg, by relying on data-based information without hiding disputes), thus providing the public a full and transparent account of policies and guidelines.

\section{Legitimize Divergent Positions and Disputes \\ Challenge: Tendency to Place Emphasis on Scientific Consensus by Hiding Disputes}

Some scientific historians assume that scientific consensus is the only way to construct scientific policy. One reason is the desire to block doubters with economic and political interests who try to sow confusion and fear in the minds of the public. ${ }^{40}$ Moreover, the majority is often concerned that a minority opinion will impede its ability to reach group consensus and convey a coherent message. Such efforts $^{17,21}$ may lead organizations to overlook groundbreaking "marginal studies."

In the social network era, the public has access to minority opinions or scientific disputes that organizations choose not to communicate. Thus, exposure to selective information can elicit public mistrust, since the public wants to be fully informed of all available information. ${ }^{41-43}$ A lack of transparency can lead the public to conclude that the organization is trying to promote a specific policy or hide information out of ulterior motives. If an organization ignores scientific disputes, the public may fail to accept the information and guidelines it is trying to promote.

The case of Kaci Hickox, a nurse who returned to the US after treating Ebola patients in Sierra Leone illustrates what happens when the public is given information that differs from the official line. Contrary to the official CDC standpoint, Kaci Hickox was quarantined at a New Jersey hospital, released after three days and required to remain in isolation for 21 days. The ensuing debate ${ }^{44,45}$ raised fundamental questions about Ebola transmission and incubation. While the health organizations did not communicate this scientific dispute ${ }^{46-49}$ for fear of generating panic, the nurse's quarantine sparked a dynamic social media debate.

At the outset of the COVID-19 pandemic, the WHO took a much wiser approach to uncertainty, while national health authorities in each country often treated uncertainties as if they were certainties. For instance, despite mounting evidence that COVID-19 is transmitted by droplet and despite WHO declarations of uncertainty regarding airborne contagion, ${ }^{50}$ Israel rushed to declare this as a certainty, affecting mask-wearing compliance.

\section{Recommendation: Legitimize Divergent Positions and Disputes}

Research examining the role of "devil's advocates" who criticize assumptions and guidelines suggested by other team members indicates that a devil's advocate can improve the quality of group decision-making. ${ }^{51}$ In addition, recent research suggests that dissenters have a positive impact on group decisions. ${ }^{52,53}$

Organizations tend to disregard minority/marginal opinions in their media campaigns, assuming that these may confuse the public. The history of science and the above studies show that organizations should heed marginal 
opinions and provide a respectful and reasoned response on social media indicating why they decided on opposing policies and guidelines. For example, during the COVID19 pandemic 12,000 scientists and medics signed a petition against the lockdown policy. ${ }^{54}$ They argued in favor of living life normally despite the virus while safeguarding at-risk population groups. But governments offered no professional response to these claims. Indeed, experts who do not share the majority opinion are not necessarily anti-science.

\section{Challenge: Public Health Experts versus "People with Agendas"}

Organizations also often attach negative labels to experts who express opposing opinions. One of the tobacco industry's most effective strategies was to launch personal attacks on scientists and experts who presented findings that undermined the industry, ${ }^{40}$ describing them as eccentric, marginal, or "people with agendas". ${ }^{11}$

Some public health policymakers have also adopted the personal attack strategy by accusing those who criticize them of being ideologues with research biases. The idea that anyone who opposes the official line has an agenda filters down into how organizations treat experts who speak out on social media. The strategy of personal attack has been used by public health professionals or policymakers during COVID-19, who described those who criticized them as "coronavirus deniers" and "anti-vaxxers."

The organizations and their representatives often dismiss the opinions of dissidents, belittle their professional background and try to silence them. Journalists and anyone who criticizes or doubts the official policy are given similar treatment.

\section{Recommendation: Welcome Other Experts Instead of Shaming Them}

The use of the term "ideologue" to label opponents of the establishment is misleading. According to the constructivist approach, ${ }^{55}$ all scientists have their own individual values. The important question is whether these scientists are self-reflective and allow their research findings to lead them on a course of exploration and discovery.

It is important to recognize that those who believe that they are the only experts are the ones who acknowledge the limits of evidence-based frameworks and hold cognitive biases. ${ }^{56-58}$ According to Houghton, ${ }^{22}$ rather than criticize the cognitive biases of their political opponents, policymakers should acknowledge the universal existence of such biases and engage their opponents with due respect.

\section{Fight Conflicts of Interest Rather Than Merely Exposing Them \\ Challenge: Conflicts of Interest That Interfere with Decision-Making}

During crises in which authorities are required to make quick decisions based on limited information, some stakeholders may attempt to interfere with the decision-making of both national and international health organizations. During health crises such as the H1N1 influenza pandemic in 2009 and the Ebola epidemic in 2013, questions arose about potential conflicts of interest among expert consultants who had financial connections with the pharmaceutical industry and who served on WHO advisory boards and the WHO Emergency Committee. ${ }^{59,60}$ While conflicts of interest among experts have been widely discussed in academic forums, in the US Congress and in the press, exposing such conflicts of interest still is problematic.

Moreover, not only do such conflicts of interest interfere with decision-making, they are also often exposed on social media. During crises, leaders use social networks to point out inherent conflicts of interest within organizations. While organizations must not avoid exposing conflicts of interest on social media, such exposure often distracts the public from the science-based information the organizations are attempting to communicate, while shifting the focus to the organization's decision-making.

\section{Recommendation: Minimize Conflicts of Interest Instead of Exposing Them}

Although exposing conflicts of interest is very important, minimizing them is even more important. Many options are available for minimizing conflicts of interest: extending the waiting period for policymakers to apply for a position in industry; prohibiting past funding; allowing different categories of stakeholders to have a voice in decision-making regarding immunization; increasing transparency; evaluating discussions in vaccine committee hearings. Private sector involvement should be expanded to include companies whose financial interests directly align with those of global health interests. ${ }^{11}$

\section{Treat the Public as Equals \\ Challenge: Assumption That the Public is Overly Emotional and Irrational}

Although experts aspire to achieve partnership with the public and despite the understanding that the public is at the center, some still maintain that those who do not follow the guidelines are irrational and motivated by 
emotions. This dichotomy is incorrect. Studies on decision-making indicate that both experts and the public make decisions based on emotional, intuitive, experiential and rational considerations. ${ }^{61}$

Policymakers lack the time, resources and cognitive competence to consider all information or to predict all the consequences of their actions. ${ }^{62,63}$ People, including experts, are "cognitive misers", 64 using informational shortcuts and heuristics to gather only enough information to make decisions.

Overall, studies on decision-making under conditions of uncertainty have shown that intuition and feelings play a significant role. ${ }^{65-67}$ Even experts use "subjective probabilities" and are prone to the same biases and errors as laymen. ${ }^{68}$ Wynne $^{69}$ claims that not only is the public capable of taking sides based on emotions, it also has "intellectual substance," meaning a capacity for common sense, although this logic does not necessarily fit institutional expert categories.

\section{Recommendation: Engage in Dialogue Between Equals}

Instead of labeling members of the public who fail to follow guidelines as irrational, organizations should address the questions and concerns the public raises on social networks and reveal the organizational considerations upon which the guidelines were based. Studies found that experts' barriers to vaccinations are similar to those of the rest of the public. ${ }^{70-72}$

Some decision-makers also assume that the public tends toward panic and hysteria. ${ }^{46}$ Yet contrary to this broadly accepted view, empirical studies reveal the opposite findings. The idea that the public is "irrational" causes organizations to become patronizing and confrontational rather than engaging in a dialogue between equals. Furthermore, thinking that the public would panic if given complete information results in providing only selective information on social media campaigns, thereby omitting any uncertainty.

\section{Consult and Recruit Risk}

\section{Communications Experts During Crises Challenge: Diminished Funding for Risk Communications Experts}

Despite the importance and need for risk communications expertise, funding for professional communications staff is diminishing worldwide. Health organizations across the globe do not always use the expertise of professionals and do not allocate resources to the task of risk communication. Most organizations think that their spokesperson or PR company can handle their EID communications. This lack of risk communication professionals at meetings to discuss ways to communicate information to the public is reflected in suboptimal communication of the information.

\section{Recommendation: Engage Risk Communications Professionals}

Despite what some decision-makers may think, health and risk communications is a professional discipline, not a branch of public relations or spokesmanship. Involving risk communications experts can help organizations design appropriate and effective social media campaigns for different population groups based on professional theories and models from the field.

\section{Path 2: Strategies for Enabling Health Organizations to Respond on Social Networks}

During the COVID-19 pandemic, the citizens of most countries across the globe were forced into lockdowns or to practice social distancing. Consequently, more than ever the social media became the arena for social interactions.

As social isolation continued, these platforms have become more important and more frequently used in communication, entertainment and socialization, and for gaining instant access to information about the pandemic. Moreover, the people and institutions in charge of managing the pandemic have begun to rely more frequently on social media platforms and the benefits they offer in risk communication. They have begun using social media to boost the public's awareness about the disease and to reinforce people's beliefs to encourage them to comply with the precautions. ${ }^{73-76}$

The paper discusses the following challenges and makes recommendations for managing each of them: (1) erroneous or false information can trigger skepticism and resistance, (2) all unofficial information is treated as misleading, (3) failure to address the public's emotional needs; and (4) framing uncertainty in terms of absolute certainty.

\section{The Battle Against Misinformation Challenge: Erroneous or False Information Can Trigger Skepticism and Resistance}

During pandemic crises, some of the information the public receives via the new media is misinformation (deficient 
information) or disinformation (intentionally false information). ${ }^{77,78}$ This erroneous information has implications for health-related decision-making and public health behavior. ${ }^{79}$ Health organizations must respond by correcting false information to gain public trust and to motivate people to follow the recommended instructions. Research indicates that inaccurate and false information can trigger skepticism and resistance among the public. ${ }^{55}$ Misinformation can also backfire, generating a reaction that is contrary to the intended response to persuasive messages.

In managing two-way communication channels in a web-based social sphere, one of the challenges facing health organizations is how to clarify partial or mistaken information for three different groups on social media (pro, hesitant and anti). While correcting misinformation is currently of primary concern in the field of health communication, there are still insufficient empirical studies to help create a theoretical infrastructure for accomplishing this in the age of new media. It is important to note that alongside deliberate disinformation by stakeholders, most of the discourse on social media stems from people's desire to obtain additional information, which is sometimes not fully conveyed by the health organizations. ${ }^{11}$

During the COVID-19 crisis, the WHO tried to cope with misinformation by using the term "infodemic", 80 coined by David J. Rothropp on May 11, 2003. This term refers to the overabundance of information-some of it accurate and some not - that makes it hard for people to find trustworthy sources and reliable guidance when they need it.

Similarly, studies show that when health organizations want to communicate facts to the public they often distinguish between myth and fact. ${ }^{81-83}$ This form of correction is not neutral and has been found to be ineffective for two reasons. First, when information provided on a website is identified as a myth, people still remember the information even though it is totally or partially untrue. Second, the public refuses to accept a judgmental approach from an organization without scientific evidence. In two studies on public attitudes towards the MMR vaccine and the seasonal flu vaccine, ${ }^{84,85}$ pro-vaccine information from the CDC website had a backfire effect in that vaccine skeptics formed even stronger negative opinions about vaccinations after being given information intended to refute the supposed connection between vaccinations and autism.

\section{Recommendation: Reframe the Pejorative Term} "Infodemic" as Something More Neutral

In their battle against misinformation, health organizations should change the pejorative framing of the term "infodemic" into something more neutral so as not to generate resistance or a boomerang effect among certain groups. For example, the WHO can use its AI-powered tool ${ }^{86}$ based in its social listening approach ${ }^{87}$ to ask subgroups in each country to suggest other names for the information and can consult with those who are hesitant or skeptical regarding how to reframe the information.

\section{Address Information Objectively Challenge: All Unofficial Information is Treated as Misleading}

Many health organizations approach today's infodemic by attempting to remove misleading information from the internet. To this end, during the COVID-19 crisis the WHO cooperated with the commercial giants Google, Facebook and Amazon. Such cooperation is welcome and important for it signals a commitment to sticking to the truth and makes it harder to spread and access misinformation. ${ }^{88-91}$ Yet a cautious assumption is that skeptical groups or hesitant members of the public believed these technology giants were infringing on their rights to ask questions and receive information openly and freely.

In her book Stuck: How Vaccine Rumors Start - and Why They do not Go Away, ${ }^{92}$ Heidi Larson claims that labeling the suspicions and doubts of those who are hesitant about the side effects of vaccinations as "misinformation" or "rumors" and therefore dismissing them is a mistake. She asserts that

vaccine anxieties are rarely simple, and the rumors are not all wrong .... Trying to delete or correct a rumor is missing the point .... Pushing rumors and the sentiments they carry underground may temporarily suppress, if not aggravate those who have strong beliefs. ${ }^{92}$

Accordingly, every rumor about an epidemiological crisis or epidemic cannot be dismissed as misinformation.

Nevertheless, health organizations tend to treat all information from unofficial sources as misleading, even though some sources contain misinformation, some involve disinformation, and some include half-truths or uncertainties. The uncertainty surrounding the source and treatment of COVID-19 generated many rumors on social media with differing levels of veracity. For example, in the early days of COVID-19, reports circulated that the virus 
had originated in a laboratory in Wuhan, China. Moreover, claims that eating garlic or drinking bleach could cure the virus were also widely disseminated. In reality, the source of the virus is a matter of uncertainty, while eating garlic to cure the virus is a misleading suggestion. Nevertheless, the health organizations, with the assistance of Google, Facebook and Amazon, dismissed items they wished to refute without exercising sufficient discrimination. ${ }^{89}$ This non-differential treatment of misleading information may cause certain people, especially those who are hesitant and skeptical, to think the organizations are trying to hide something because they do not practice transparency in dealing with this misinformation.

\section{Recommendation: Treat Information Objectively}

To combat this indiscriminate removal of information, health organizations should address each piece of information objectively and differentiate between various types of information. Larson discusses the importance of the "ecology of rumors", that is, the importance of determining the type of rumor, the fertile ground, the spreaders of the rumor and the patterns of spread. ${ }^{92}$

Accordingly, health organizations should map out information using crowdsourcing, as they have done in other areas, and then create categories for the different types of information disseminated during the epidemic crisis.

\section{Use Narratives to Consider Emotional Aspects}

\section{Challenge: Failure to Address the Public's Emotional Needs}

Emotions have long been acknowledged as an essential ingredient in the recipe for persuasion. ${ }^{93-95}$ Persuasive health messages that arouse people's emotions are usually perceived as more effective than less emotional messages. ${ }^{96-100}$ Despite this, organizations tend to correct misinformation by providing "dry" data and using figures rather than addressing the public's emotional needs and concerns. ${ }^{13}$ The literature indicates that health authorities worldwide tend to ignore the emotional element, and by doing so miss out on engaging in effective dialogue with the public.

\section{Recommendation: Use Narrative to Address the Public's Emotional Needs}

One way to address the need to include emotional aspects in how organizations transmit information to the public is through the use of narrative. ${ }^{101}$ A narrative is defined as a representation of connected events and characters that has an identifiable structure, is bounded in space and time, and contains implicit or explicit messages about the topic being addressed. ${ }^{102}$

Narrative humanizes dry scientific facts by engaging the human voice of both narrator and listener. ${ }^{103}$ Through emotional arousal, narrative has the power to influence listeners' beliefs ${ }^{104}$ and teach new behaviors. ${ }^{105,106}$

Hopfer and Clippard ${ }^{107}$ identify five qualities that make narrative messages particularly promising for health interventions: overcoming resistance toward the advocated health behavior; engaging less involved audiences; reaching audiences whose knowledge is limited; rendering complex information comprehensible; and grounding messages in the cultures and experiences of the target audience.

Using narrative and describing the authentic stories of various groups can reduce stigmas and fears toward these groups. For example, during COVID-19, telling stories about patients from different minority groups and how they coped while maintaining their confidentiality can be used to evoke empathy toward these groups. This will help reduce the public's hostile attitudes toward these groups (eg, in Japan during COVID-19 $9^{108}$ ) in general and in the social media in particular.

The use of narrative evidence as a tool for changing attitudes and behaviors is effective not only for long periods of clinical care intervention, but also for short ones, because both require the public to change its behavior. Indeed, the COVID-19 pandemic is forcing the public to make ongoing lifestyle changes. During a crisis or a pandemic, policymakers must actually compete for the public's attention with other sources that may be disseminating misinformation. In such a complex multimedia environment, the use of narrative has many advantages.

\section{Acknowledge and Proclaim Uncertainty Challenge: Framing Uncertainty in Terms of Absolute Certainty}

Throughout the pandemic, the public has sought clear and reliable advice from their governments. An ongoing situation of uncertainty such as the COVID-19 pandemic often leads health organizations to communicate conflicting or scientifically controversial guidelines to the public. Many governments stuttered at the start of the pandemic, and were slow to provide clarity and certainty. ${ }^{109}$

One example pertains to the guideline surrounding wearing masks. The literature reflects uncertainty 
regarding the effectiveness of wearing masks, with some studies indicating that wearing a mask can lead to false confidence. ${ }^{110-112}$ The uncertainty at the beginning of the crisis regarding how the coronavirus is transmitted (by droplets or airborne) also contributed to the debate regarding the applicability of masks and the degree to which they protect against contagion. ${ }^{50}$ In light of uncertainty and conflicting guidelines, the public is forced to seek information from unofficial sources on social networks. On the one hand, these social media users become more aware and knowledgeable about the current uncertainty, while on the other hand they become more creative in searching for and creating information. Hence, health organizations must communicate uncertainty in a way that is accessible and fluent to the public.

The literature indicates that in situations of uncertainty, policymakers do not always provide full information. Instead, they use scientific knowledge to frame uncertainty in terms of absolute certainty. ${ }^{113,114}$ van Asselt and Vos ${ }^{113}$ called this "the uncertainty paradox," referring to situations wherein uncertainty is acknowledged but the role of science is framed as providing certainty. ${ }^{115}$

The attempt to use conclusive language often leads to the use of military terminology. Officials commonly discuss the COVID-19 crisis in terms of war, flattening the curve, integrating the event, a war against the virus, enemy, a battle for the hearts and minds of the people. Not only is the transition from health and medical language to military language symbolic. It also indicates what the authorities think about conveying information to the public. This approach often conflicts with the essence of scientific language as a language of inquiry and doubt that communicates uncertainty wherever it exists. ${ }^{116}$

\section{Recommendation: Acknowledge and Proclaim Uncertainty}

The solution to this challenge is to employ a strategy that acknowledges and proclaims uncertainty. Sandman and Lanard $^{117}$ emphasize the need to "proclaim uncertainty," advising authorities to share tentative information if that is all they have. Studies have indicated that in situations of risk $^{42}$ and uncertainty ${ }^{41}$ the public wants full transparency.

Transparent communication does not provoke negative reactions among the public, but rather helps reduce negative feelings and increases the public's respect for the riskassessing agency. ${ }^{118}$ Indeed, transparent communication creates an autonomy-supportive health care climate, provides choice and applies a bottom-up approach to communication by generating solidarity. ${ }^{119}$ In addition, health organizations should invest in evaluation, use scientific language, and develop tools and skills for each country to apply in future crises.

\section{Path 3: Engage the Public on Social Media}

The third path entails using "more social" means by engaging the public as a partner and tailoring the information provided by health organizations to the concerns and needs of different population groups.

The paper discusses the following challenges and makes recommendations for managing each of them: (1) the dualistic paradigm of ignorant public versus knowledgeable experts is no longer relevant; (2) the public is insufficiently engaged in solving complex global problems; (3) demographic factors influence risk understanding and interpretation; and (4) different groups are not considered in decision-making.

\section{Promote "Citizen Science"}

Challenge: The Dualistic Paradigm of Ignorant Public versus Knowledgeable Experts is No Longer Relevant

Irwin's concept of "citizen science" 120 demonstrates that the dualistic paradigm of an ignorant public versus knowledgeable experts is no longer relevant. According to the UK report titled "Science as an Open Enterprise", the growth of the citizen science movement could turn out to be a major shift in the social dynamics of science by "blurring the professional/amateur divide and changing the nature of the public engagement with science". ${ }^{92}$

The technological climate of the 21st century promotes diverse voices and perspectives on knowledge rather than one monolithic perspective, indicating that the public is capable of understanding science differently in diverse contexts.

\section{Recommendation: Promote Citizen Science Projects}

The notion of the "citizen scientist" has gained increasing prominence in many contexts, which have recognized that reciprocal partnership and engagement among researchers, citizens and policymakers is a key to the success of multistakeholder initiatives. ${ }^{121}$ Numerous online projects have been created to promote "public science" based on the understanding that the public can gather information, read about science, and make decisions. These projects have led to the establishment of many centers of 
participatory research, such as the Public Science Project and the Society for Participation, Engagement, Action and Knowledge. $^{122}$

The participatory approach has the potential to promote various interested parties, among them civic non-profit organizations such as OGP, as partners during epidemiological crises at both the national and the international levels. $^{123}$ By means of such platforms, the public has increasingly chosen to gather and manage the information it needs rather than relying only on the authorities. Once organizations accept the assumption that the public is capable of understanding science, they can translate this approach into several strategies.

For example, Open Humans ${ }^{124}$ is a community of close to 9000 members who conduct "self-research" by sharing personal data for analysis by the community. Some of the data shared by the participants is genetic information. One of the community's most recent projects, Quantified Flu, relies on data uploaded from participant wearables, such as smartwatches. The project originated in a community call among participants who were already collecting, sharing and analyzing their personal data. In response to the global pandemic, they felt motivated to do something with that data.

\section{Use Crowd Wisdom to Create Open Innovation \\ Challenge: Insufficient Public Engagement in Solving Complex Global Problems}

Chesbrough $^{125}$ coined the concept of Open Innovation to describe how the public can contribute creative ideas on different subjects to promote products. He suggested that commercial companies join forces within their communities and through external partnerships with other stakeholders to develop creative solutions.

The stage of public engagement with the digital world not only entails an active search for relevant information. It also represents an attempt to receive answers to questions or problems from members of the public, not necessarily experts or doctors, and to consult not only one or two of them, but rather a diverse group. ${ }^{126}$

\section{Recommendation: Use Crowdsourcing to Solve Complex Global Health Problems}

Don Joseph, chief executive of the California-based NGO BIO Ventures for Global Health, declared that the

Challenge is to create projects that are simple and allow a streamlined process for organizations to participate ....
[Open innovation partnerships could] significantly reduce trial and error, and lead neglected disease researchers to that 'Eureka moment' more quickly and effectively. ${ }^{127}$

Some financial companies and intelligence communities have implemented this notion of crowdsourcing and now consult a variety of experts around the world on different issues. In the field of health, the concept of crowdsourcing may be effective in finding solutions for complex global problems. Collaborations already exist between pharmaceutical companies, academic researchers, disease advocates, and even the general public. ${ }^{126}$ Health organizations can take this idea one step further by using digital crowdsourcing to think about predicting future epidemics and addressing scientific dilemmas. The goal is to collect decentralized, varied and diverse information from all sorts of people who choose to be part of the effort, while the organization that is managing the epidemic crisis gathers and integrates all of the data. Methodological and statistical approaches are now available to promote highquality citizen science crowdsourcing. Collaborative models of science should be inherent to the spectrum of citizen science projects. $^{128}$

The public sphere would function better as a system in times of crisis if the WHO were to interact with various groups in the public on an ongoing basis, like in the WHO recent social listening approach. ${ }^{86,87}$ The culture of inclusion should be established not only during crises, but as a systemic continuum for digital crowdsourcing risk communication management.

\section{Adapt and Tailor Messages to Diverse Groups \\ Challenge: Demographic Factors Influence Risk Understanding and Interpretation}

People understand and interpret risks differently based on various factors, including gender, education level, income, culture, and ethnicity. The importance of tailoring and adapting information to different population subgroups is crucial in the context of epidemics and vaccinations. ${ }^{16,129-132}$ According to the social amplification of risk framework, ${ }^{133}$ risk events interact with the psychological, social and other cultural components of groups along paths that either increase or decrease public perceptions of risk. Different groups have varying abilities to cope with risks and with the social and economic implications of these risks. 
Health authorities erroneously believe the public does not have the capacity to understand scientific uncertainty and therefore needs to be given clear instructions and simplistic messages. This perception is expressed by the "information deficit model", ${ }^{134}$ which distinguishes between experts who have the information and nonexperts who lack information and understanding and are somewhat ignorant of scientific knowledge regarding risk and probability. Yet each population group, even those who are illiterate, has the right and the capacity to understand the rationale behind the guidelines issued by health organizations.

\section{Recommendation: Tailor Information According to Local Level Segmentation}

Organizations must tailor their messages according to socioeconomic, cultural, educational and other contexts, rather than using "one-size fits all" messaging. ${ }^{135,136}$ There is a difference between flattening information based on the belief that some people cannot understand it and tailoring information to the receiver. Tailoring information does not entail providing partial or selective information but rather using methods to convey full information thoughtfully and appropriately.

Through the use of mental models, ${ }^{137}$ ie, research on how different audiences perceive and understand the risk, media campaigns can be tailored to the cognitive and linguistic understand and level of literacy of each population sub-group in different countries. In the case of COVID-19, these mental models can be used to identify how different target audiences perceive the coronavirus illness and the ways of preventing and treating it. The objective of using mental models in empirical research is not to persuade the public to obey the government's guidelines but rather to identify the information the public needs to make intelligent decisions regarding coping with, preventing and treating COVID-19 (eg, medications and vaccination to prevent the illness).

Indeed, international health authorities have addressed the need for local segmentation in their outbreak communication guidelines and reports. The main questions and concerns the public raises on social media forums during pandemic outbreaks should be identified and analyzed according to the specific profiles of the target audiences that raise these concerns in each country. Accomplishing this presents a special challenge due to the segmentation of the public during a pandemic crisis. Several issues are likely to emerge, such as accounting for the specific language usage (eg, slang) of diverse population groups and accounting for culture-specific reactions and norms of communication between members of particular subgroups. ${ }^{11}$

This challenge leads to the conclusion that the WHO should provide ongoing guidance and training for policymakers and managers, both locally and internationally, with the goal of studying and constructing cultural and social profiles of the people they must serve in times of crisis, like in the venue of the 1st and 2nd WHO Infodemic Manager trainings. ${ }^{138,139}$

\section{Encourage Discourse and Informed Decision-Making Challenge: Different Groups are Not Considered in Decision-Making}

One of the challenges facing health authorities worldwide is the need to create trust among different groups, including those that are hesitant about or even object to vaccinations. According to the WHO report for 2008,

The next decade is likely to be volatile and uncertain. Continuing mass urbanization and migration, population growth, geopolitical uncertainty and conflict, and natural disasters and environmental disruption will present major challenges to national immunization systems. ${ }^{140}$

\section{Recommendation: Invest in Risk Communication for Diverse Groups}

Hesitant groups are made up of individuals who were born during the New Media age and want to control their lives and the lives of their children. As Larson asserted, "Young parents trust themselves and their own decisions more than a system they feel has disappointed them, alienates them, and disempowers personal beliefs". ${ }^{2}$

In the context of epidemics, health organizations should invest more resources in encouraging research on how different groups make decisions regarding healthrelated issues before and during epidemics.

\section{Recommendation: Implement the Convergence Communication Approach}

During a global pandemic crisis such as the COVID-19 crisis, communication with various groups in the public is a recurring circular process in which the public raises fears and questions and the organization must provide answers. This process recurs until the point of convergence, ${ }^{141,142}$ when the parties find a common ground. Both in crises and in routine times, health organizations should maintain 
regular and ongoing two-way communication with laypeople, scientific experts and other expert third parties. Each country should elect representatives from diverse subgroups in the population based on characteristics such as age, gender, ethnicity, culture, religion, attitudes and health literacy. These diverse representatives will be capable of providing a fair and culturally adapted representation of the local and social context in each country. ${ }^{143-147}$ This dialogue should include both supporters and dissenters. A parliament should be established to represent subgroups specific to each country to consider input from three groups - opinion leaders, experts, and citizens - on issues that do not have "scientific solutions". Blogs or forums can simulate two-way communication about public health concerns and possible responses that can be used to test possible interactions between the public and government organizations regarding health messages and risk communicators. $^{11}$

Moreover, health organizations should include representatives from all groups (eg, hesitant and anti-vaccination groups as well as pro-vaccination groups) in order to enhance decision-making and informed consent. More thorough and informed decision-making can lead to greater behavior internalization.

\section{Limitations}

In this perspective paper we chose to focus on the internal organizational media discourse and its impact on the strategies health organizations adopt on social media. Note, however, that many other issues that have arisen during the COVID-19 crisis, among them isolation, loneliness, higher rates of depression, and anxiety, must be addressed by health organizations through dynamic and ongoing dialogue with the public. These issues were not expanded upon in this perspective paper, although their importance was emphasized in various examples. The implications of the COVID-19 crisis on the public's mental and physical well-being need to be further explored in order to develop a scientific infrastructure that will help health organizations communicate information in subsequent crises.

Since we are still in the midst of the dynamic and ongoing COVID-19 crisis, we have chosen to focus on the present while taking the past into consideration (ie, managerial and communicative aspects reflected in previous health crises). After the COVID-19 crisis comes to an end, we recommend further research on strategic planning in response to the crisis from the perspective of time.

\section{Conclusions}

This paper demonstrates the discrepancies between the approaches in the health and risk communication professional literature and their actual implementation in the field, both in the culture of the organizations themselves and in the way these organizations communicate health information to the public. Moreover, in addition to this lack of implementation of theory, often the organizations adopt a contrary approach that is not recommended in the literature (eg, organizational groupthink, anxiety about scientific consensus that leads to hiding disputes, framing risk responses in terms that stigmatize and dismiss critics and oppositional voices, or using an approach to public understanding framed primarily in terms of deficit).

All of this leads us to ask why, despite all the existing knowledge, not much is being implemented in practice? Many hypothetical answers to this question can be raised. Here I propose several answers based on research conducted by myself and others. I qualify these answers by the disclaimer that these directions should continue to be examined through additional empirical studies.

First, most health organizations, and mainly governmental organizations, are still quite based on an organizational structure that is primarily hierarchical and much less cooperative and democratic, and this structure affects how information is processed and disseminated. ${ }^{116}$ Second, many public health employees in key positions in government and health organizations still use paternalistic thought patterns. In addition, the experts who manage the policy of government ministries perceive any disagreements in how they chart government policy as a threat to their professional status. ${ }^{148,149}$ Moreover, they fear that as soon as such controversy is exposed, the public will not comply with their decisions. ${ }^{148}$

Furthermore, epidemiological crises are often marked by ego conflicts between experts from the various fields. See, for example, the disagreements among the various experts during the COVID-19 crisis, as exemplified in our research, ${ }^{150}$ such that each expert thinks he or she represents "pure science", which is of course erroneous. Indeed, when science is associated with lifestyle, politics and values assume a central role. In such a case, theories related to communications, sociology and psychology should be implemented in line with the social and political context. Until people gain an in-depth understanding of this, there can be no genuine attempt to integrate models from these fields. In addition, some of the public 
health experts who lead government ministry policy during epidemiological crises see themselves as the main experts, so they have much less patience for hearing experts from other "softer" fields, such as risk communications or social and cognitive psychology.

In the follow section, I outline several recommendations that can help change the approach and encourage consultation and scientific discourse.

\section{Recommendations}

\section{Putting More "Social" Content into Health Organizations' Culture}

To communicate more effectively on social media, health organizations must become "more social" within their own organizational culture by changing the ways they engage with experts who disagree with the scientific consensus. In this perspective paper, we suggest five strategies for changing the organizational culture: (1) engage in professionally and intellectually diverse decision-making; (2) grant legitimacy to deviant positions and disputes; (3) fight conflicts of interest rather than merely exposing them; (4) treat the public as equals; (5) consult and recruit risk communication experts before and during crises.

\section{Strategies to Enable Health Organizations to Respond to the Public on Social Networks}

To make information and the way it is communicated "more social," health organizations must go beyond simply correcting misinformation and relying on the prevailing model of generic questions and answers. In this perspective paper, we suggest the following tactics and strategies: (1) battle misinformation by reframing the pejorative term "infodemic" as something more neutral; (2) address each piece of information objectively and differentiate between various types of information; (3) use narratives instead of trying to correct or fix information and address the public's concerns and fears; (4) acknowledge and proclaim uncertainty.

\section{Engaging the Public on Social Media}

A third path toward making health information communication "more social" includes welcoming ideas and recommendations from the public and tailoring organizational information to the concerns and needs of different population groups, in particular those that are skeptical about the official recommendations. In this perspective paper, we propose six recommended strategies and tactics: (1) promote "citizen science"; (2) use crowd wisdom to generate open innovation that will mobilize creative ideas from the public; (3) adapt and tailor messages to subgroups in the population using segmentation on the local level; (4) encourage discourse and informed decision-making; (5) build a community presence on social media when a crisis is imminent; (6) build an automated system for assessing social media discourse to inform real-time communication.

\section{Abbreviations}

AI, Artificial Intelligence; CDC, Centers for Disease Control and Prevention; EID, Emerging Infectious Disease; IC, Internal Communications; ICT, Information and Communications Technology; WHO, World Health Organization.

\section{Ethics Approval and Consent to Participate}

Because the study was based on public knowledge and not on human subjects, it was exempt from human subjects' ethics approval by the Ethics Committee of The Faculty of Social Welfare and Health Sciences at the University of Haifa, and no consent to participate was required.

\section{Funding}

There is no funding to report.

\section{Disclosure}

The author reports no conflicts of interest in this work.

\section{References}

1. Tell Me [homepage on the Internet]. Available from: https://www.tell meproject.eu/. Accessed July 7, 2021.

2. ASSET. [homepage on the Internet]. Available from: http://www.assetscienceinsociety.eu/. Accessed July 7, 2021.

3. Gesser-Edelsburg A, Shir-Raz Y, Hayek S, Aassaraf S, Lowenstein L. Despite awareness of recommendations, why do health care workers not immunize pregnant women? Am J Infect Control. 2017;45 (4):436-439. doi:10.1016/j.ajic.2016.11.025

4. Gesser-Edelsburg A, Walter N, Green MS. Health care workers-part of the system or part of the public? Ambivalent risk perception in health care workers. Am J Infect Control. 2014;42(8):829-833. doi:10.1016/j. ajic.2014.04.012

5. Gesser-Edelsburg A, Shir-Raz Y, Hayek S, Sassoni-Bar Lev O. What does the public know about Ebola? The public's risk perceptions regarding the current Ebola outbreak in an as-yet unaffected country. Am J Infect Control. 2015;43(7):669-675. doi:10.1016/j. ajic.2015.03.005 
6. Gesser-Edelsburg A, Walter N, Shir-Raz Y. The "new public" and the "good ol' press": evaluating online news sources during the 2013 polio outbreak in Israel. Health Commun. 2017;32 (2):169-179. doi:10.1080/10410236.2015.1110224

7. Gesser-Edelsburg A, Shir-Raz Y. Science vs. fear: the Ebola quarantine debate as a case study that reveals how the public perceives risk. J Risk Res. 2017;20(5):611-633. doi:10.1080/ 13669877.2015.1100659

8. Gesser-Edelsburg A, Stolero N, Mordini E, Billingsley M, James JJ, Green MS. Emerging infectious disease (EID) communication during the 2009 H1N1 influenza outbreak: literature review (2009-2013) of the methodology used for EID communication analysis. Disaster Med Public Health Prep. 2015;9 (2):199-206. doi:10.1017/dmp.2014.126

9. Gesser-Edelsburg A, Walter N, Shir-Raz Y, Green MS. Voluntary or mandatory? The valence framing effect of attitudes regarding HPV vaccination. $J$ Health Commun. 2015;20(11):1287-1293. doi:10.1080/10810730.2015.1018642

10. Gesser-Edelsburg A, Shir-Raz Y, Green MS. Why do parents who usually vaccinate their children hesitate or refuse? General good vs. individual risk. $J$ Risk Res. 2016;19(4):405-424. doi:10.1080/ 13669877.2014.983947

11. Gesser-Edelsburg A, Shir-Raz Y. Risk Communication and Infectious Diseases in an Age of Digital Media. London and New York: Routledge; 2016.

12. Gesser-Edelsburg A, Shir-Raz Y, Walter N, et al. The public sphere in emerging infectious disease communication: recipient or active and vocal partner? Disaster Med Public Health Prep. 2015;9(4):447-458. doi:10.1017/dmp.2015.31

13. Gesser-Edelsburg A, Diamant A, Hijazi R, Mesch GS. Correcting misinformation by health organizations during measles outbreaks: a controlled experiment. PLoS One. 2018;13(12):e0209505. doi:10.1371/journal.pone.0209505

14. Manheim D, Gesser-Edelsburg A. The structure of tweets about vaccine safety between health organizations, experts and the public: analyzing risk communication conversations. Disaster Med Public Health Prep. 2020;1-25. doi:10.1017/dmp.2020.404

15. Ratzan SC, Moritsugu KP. Ebola crisis-communication chaos we can avoid. $J$ Health Commun. 2014;19(11):1213-1215. doi:10.1080/10810730.2014.977680

16. Abrams EM, Greenhawt M. Risk communication during COVID-19. $J$ Allergy Clin Immunol Pract. 2020;8 (6):1791-1794. doi:10.1016/j.jaip.2020.04.012

17. Janis IL. Groupthink: Psychological Studies of Policy Decisions and Fiascoes. Boston: Houghton Mifflin; 1982.

18. Schwenk CR. Strategic decision making. J Manage. 1995;21 (3):471-493. doi:10.1177/014920639502100304

19. Kahneman D, Klein G. Conditions for intuitive expertise: a failure to disagree. Am Psychol. 2009;64(6):515-526. doi:10.1037/a0016755

20. Rosenthal U, Hart P. Experts and decision makers in crisis situations. Knowledge. 1991;12(4):350-372. doi:10.1177/ 107554709101200402

21. Turner ME, Pratkanis AR. Twenty-five years of groupthink theory and research: lessons from the evaluation of a theory. Organ Behav Hum. 1998;73(2):105-115. doi:10.1006/obhd.1998.2756

22. Houghton DP. Invading and occupying Iraq: some insights from political psychology. Peace Confl. 2008;14(2):169-192. doi:10.1080/10781910802017297

23. Report of a Committee of Privy Counsellors. The report of the Iraq inquiry. GOV.UK. Available from: https://www.gov.uk/gov ernment/publications/the-report-of-The-iraq-inquiry. July 6, 2016. AccessedNovember 10, 2020.
24. Hoever IJ, van Knippenberg D, van Ginkel WP, Barkema HG. Fostering team creativity: perspective taking as key to unlocking diversity's potential. J Appl Psychol. 2012;97(5):982-996. doi:10.1037/a0029159

25. van Knippenberg D, De Dreu CKW, Homan AC. Work group diversity and group performance: an integrative model and research agenda. Am J Appl Psychol. 2004;89(6):1008-1022. doi:10.1037/0021-9010.89.6.1008

26. Schulz-Hardt S, Brodbeck FC, Mojzisch A, Kerschreiter R, Frey D. Group decision making in hidden profile situations: dissent as a facilitator for decision quality. J Pers Soc Psychol. 2006;91(6):1080-1093. doi:10.1037/0022-3514.91.6.1080

27. Baron R, Kerr N. Group Process, Group Decision, Group Action. Buckingham: Open University Press; 2003.

28. Garner JT, Ragland JP. Tabling, discussing, and giving in: dissent in workgroups. Group Dyn Theory Res Pract. 2019;23(1):57-74. doi: $10.1037 / \mathrm{gdn} 0000098$

29. De Dreu CKW, West MA. Minority dissent and team innovation: the importance of participation in decision making. Am J Appl Psychol. 2001;86(6):1191-1201. doi:10.1037/00219010.86.6.1191

30. Finkelstein S, Hambrick DC. Top-management-team tenure and organizational outcomes: the moderating role of managerial discretion. Adm Sci Q. 1990;35(3):484-503. doi:10.2307/2393314

31. van Dijk H, van Engen ML, van Knippenberg D. Defying conventional wisdom: a meta-analytical examination of the differences between demographic and job-related diversity relationships with performance. Organ Behav Hum. 2012;119 (1):38-53. doi:10.1016/j.obhdp.2012.06.003

32. Larrick RP. Debiasing. In: Koehler DJ, Harvey N, editors. Blackwell Handbook of Judgment and Decision Making. Oxford: Blackwell Publishing; 2004.

33. Stohl C. Organizational Communication: Connectedness in Action. Thousand Oaks, CA: Sage Publications Inc; 1995.

34. Cornelissen J. Corporate Communication: A Guide to Theory and Practice. Thousand Oaks, CA: Sage Publications Inc.; 2004.

35. Scoble R, Israel S. Naked Conversations: How Blogs are Changing the Way Businesses Talk to Customers. Hoboken, NJ: John Wiley \& Sons; 2006.

36. McGuire D, Cunningham JEA, Reynolds K, Matthews-Smith G. Beating the virus: an examination of the crisis communication approach taken by New Zealand Prime Minister Jacinda Ardern during the Covid-19 pandemic. Hum Resour Dev Int. 2020;23 (4):361-379. doi:10.1080/13678868.2020.1779543

37. Wilson S. Three reasons why Jacinda Ardern's coronavirus response has been a masterclass in crisis leadership. The Conversation; April 6, 2020. Available from: https://theconversa tion.com/three-reasons-why-jacinda-arderns-coronavirusresponse-has-been-a-masterclass-in-crisis-leadership-135541. Accessed November 20, 2020.

38. Watson VB. Five Coronavirus Success Stories Different, but the Same. Daniel K. Inouye Asia-Pacific Center for Security Studies; 2020.

39. Cairney P, Kwiatkowski R. How to communicate effectively with policymakers: combine insights from psychology and policy studies. Palgrave Commun. 2017;3(1):37. doi:10.1057/s41599017-0046-8

40. Oreskes N, Conway EM. Merchants of Doubt: How a Handful of Scientists Obscured the Truth on Issues from Tobacco Smoke to Global Warming. New York: Bloomsbury Press; 2011.

41. Palenchar MJ, Heath RL. Another part of the risk communication model: analysis of communication processes and message content. J Public Relat Res. 2002;14(2):127-158. doi:10.1207/ S1532754XJPRR1402_3 
42. Slovic P. The construction of preference. Am Psychol. 1995;50 (5):364-371. doi:10.1037/0003-066X.50.5.364

43. Frewer L, Hunt S, Brennan M, Kuznesof S, Ness M, Ritson C. The views of scientific experts on how the public conceptualize uncertainty. $J$ Risk Res. 2003;6(1):75-85. doi:10.1080/ 1366987032000047815

44. Wulfhorst E, Morgan D. CDC says returning Ebola medical workers should not be quarantined. Reuters. Available from: http://www.reuters.com/article/2014/10/28/us-health-ebola-usanewyork-idUSKBNOIG12920141028. October 27, 2014. AccessedNovember 10, 2020.

45. Zernike K, Fitzsimmons EG. Threat of lawsuit could test maine's quarantine policy. The New York Times. Available from: http:// www.nytimes.com/2014/10/30/us/kaci-hickox-nurse-under-ebolaquarantine-threatens-lawsuit.html?_r=0. October 29, 2014. AccessedNovember 10, 2020.

46. Sandman P. Ebola in the U.S. (so far): the public health establishment and the quarantine debate. The Peter M. Sandman Risk Communication Website; November 15, 2014. Available from: http://www.psandman.com/col/Ebola-4.htm. Accessed May 14, 2016.

47. Howell T. Airborne Ebola spread can't be ruled out, docs from infamous 'Hot Zone' episode say. The Washington Times; 2014 Available from: http://www.washingtontimes.com/news/2014/oct/ 16/airborne-ebola-outbreak-in-monkeys-raises-possibil/?page=all. Accessed August 18, 2021.

48. Dalgard DW, Hardy RJ, Pearson SL, et al. Combined simian hemorrhagic fever and Ebola virus infection in cynomolgus monkeys. Lab Anim Sci. 1992;42(2):152-157.

49. Weingartl HM, Embury-Hyatt C, Nfon C, Leung A, Smith G, Kobinger G. Transmission of Ebola virus from pigs to non-human primates. Sci Rep. 2012;2(1):811. doi:10.1038/srep00811

50. World Health Organization. Modes of Transmission of Virus Causing COVID-19: Implications for IPC Precaution Recommendations. Scientific Brief.. Geneva: World Health Organization; 2020.

51. Schwenk CR. Effects of devil's advocacy and dialectical inquiry on decision making: a meta-analysis. Organ Behav Hum. 1990;47 (1):161-176. doi:10.1016/0749-5978(90)90051-A

52. Jetten J, Hornsey MJ. Rebels in Groups: Dissent, Deviance, Difference and Defiance. Malden, MA: Wiley-Blackwell; 2011.

53. Levine JM, Marques JM. Norm violators as threats and opportunities: the many faces of deviance in groups. Group Process Intergroup Relat. 2016;19(5):545-552. doi:10.1177/ 1368430216657415

54. Andrews L, Blanchard S. Now 12,000 scientists and medics have signed anti-lockdown petition that urges officials to let Covid-19 spread among young and healthy people. Daily Mail. 2020 October 8

55. Bennett P, Calman K, Curtis S, Fischbacher-Smith D. Risk Communication and Public Health. 2nd ed. Oxford: Oxford University Press; 2010

56. Cassidy MF, Buede D. Does the accuracy of expert judgment comply with common sense: caveat emptor. Manag Decis. 2009;47(3):454-469. doi:10.1108/00251740910946714

57. Gregg AP, Mahadevan N, Sedikides C. The SPOT effect: people spontaneously prefer their own theories. $Q J$ Exp Psychol. 2017;70(6):996-1010. doi:10.1080/17470218.2015.1099162

58. Perez O. Can experts be trusted and what can be done about it? Insights from the biases and heuristics literature. In: Alemanno A, Sibony AL, editors. Nudge and the Law: A European Perspective. Portland, OR: Hart Publishing; 2017:115-138.

59. Cohen D, Carter P. WHO and the pandemic flu "conspiracies". BMJ. 2010;340(7759):1274-1279. doi:10.1136/bmj.c2912

60. Epstein H. Flu Warning: Beware the Drug Companies!. New York: The New York Review of Books; 2011.
61. Slovic P, Finucane ML, Peters E, MacGregor DG. Risk as analysis and risk as feelings: some thoughts about affect, reason, risk, and rationality. Risk Anal. 2004;24(2):311-322. doi:10.1111/ j.0272-4332.2004.00433.x

62. Simon HA. Administrative Behavior: A Study of Decision-Making Processes in Administrative Organization. 4th ed. New York: Free Press; 1997.

63. Cairney P, Heikkila T. Comparison of theories of the policy process. In: Weible CM, Sabatier PA, editors. Theories of the Policy Process. 4th ed. New York, NY: Routledge; 2017:301-327.

64. Kam CD. Who toes the party line? Cues, values, and individual differences. Political Behav. 2005;27(2):163-182. doi:10.1007/ s11109-005-1764-y

65. Klein G. Sources of Power: How people Make Decisions. Cambridge, MA: MIT Press; 1998.

66. Haidt J. The emotional dog and its rational tail: a social intuitionist approach to moral judgment. Psychol Rev. 2001;108 (4):814-834. doi:10.1037/0033-295X.108.4.814

67. Kahneman D, Frederick S. Representativeness revisited: attribute substitution in intutive judgment. In: Gilovich T, Griff D, Kahneman D, editors. Heuristics and Biases. New York: Cambridge University Press; 2002:49-81.

68. Tversky A, Kahneman D. Judgment under uncertainty: heuristics and biases. Science. 1974;185(4157):1124-1131. doi:10.1126/ science.185.4157.1124

69. Wynne B. Creating public alienation: expert cultures of risk and ethics on GMOs. Sci Cult (Lond). 2001;10(4):445-481. doi:10.1080/09505430120093586

70. Smedley J, Poole J, Waclawski E, et al. Influenza immunisation: attitudes and beliefs of UK healthcare workers. Occup Environ Med. 2007;64(4):223-227. doi:10.1136/oem.2005.023564

71. Weingarten S, Riedinger M, Bolton LB, Miles P, Ault M, Barriers to influenza vaccine acceptance. A survey of physicians and nurses. Am J Infect Control. 1989;17(4):202-207. doi:10.1016/ 0196-6553(89)90129-6

72. Willis BC, Wortley P. Nurses' attitudes and beliefs about influenza and the influenza vaccine: a summary of focus groups in Alabama and Michigan. Am J Infect Control. 2007;35(1):20-24. doi:10.1016/j.ajic.2006.07.009

73. Park S, Han S, Kim J, et al. COVID-19 discourse on Twitter in four asian countries: case study of risk communication. $J$ Med Internet Res. 2021;23(3):e23272. doi:10.2196/23272

74. Sleigh J, Amann J, Schneider M, Vayena E. Qualitative analysis of visual risk communication on twitter during the Covid-19 pandemic. BMC Public Health. 2021;21(1):810. doi:10.1186/ s12889-021-10851-4

75. Sutton J, Renshaw SL, Butts CT. The first 60 days: American public health agencies' social media strategies in the emerging COVID-19 pandemic. Health Secur. 2020;18(6):454-460. doi: $10.1089 /$ hs.2020.0105

76. Tosyalı H, Tosyalı F. Risk communication and social media: COVID-19 pandemic planning and response in Turkey. In: Sar1 G, editor. Handbook of Research on Representing Health and Medicine in Modern Media. Hershey, PA: IGI Global; 2021:150-171.

77. Kouzy R, Abi Jaoude J, Kraitem A, et al. Coronavirus goes viral: quantifying the COVID-19 misinformation epidemic on Twitter. Cureus. 2020;12(3):e7255-e7255. doi:10.7759/cureus. 7255

78. Tasnim S, Hossain MM, Mazumder H. Impact of rumors and misinformation on COVID-19 in social media. J Prev Med Public Health. 2020;53(3):171-174. doi:10.3961/jpmph.20.094

79. Sharma K, Seo S, Meng C, Rambhatla S, Liu Y. COVID-19 on social media: analyzing misinformation in Twitter conversations; 2020. Available from: https://arxiv.org/abs/2003.12309. Accessed August 18, 2021. 
80. World Health Organization. WHO ad-hoc technical consultation on managing the COVID-19 infodemic 7-8 April 2020. Geneva; September 15, 2020. Available from: https://www.who.int/publica tions/i/item/9789240010314. Accessed November 10, 2020.

81. Baxendale S, O'Toole A. Epilepsy myths: alive and foaming in the 21st century. Epilepsy Behav. 2007;11(2):192-196. doi:10.1016/j.yebeh.2007.04.019

82. Manyibe EO. Top ten cancer myths. J Appl Rehabil Couns. 2006;37(2):36.

83. Miller K. Book review: girls' violence: myths and realities. Youth Violence Juv Justice. 2007;5(3):207-210. doi:10.1177/ 1541204006296166

84. Nyhan B, Reifler J. Does correcting myths about the flu vaccine work? An experimental evaluation of the effects of corrective information. Vaccine. 2015;33(3):459-464. doi:10.1016/j. vaccine.2014.11.017

85. Nyhan B, Reifler J, Richey S, Freed GL. Effective messages in vaccine promotion: a randomized trial. Pediatrics. 2014;133(4): e835-e842. doi:10.1542/peds.2013-2365

86. Purnat TD, Vacca P, Czerniak, C, Ball S, Burzo S. Zecchin T, et al. Infodemic signal detection during the COVID-19 pandemic: development of methodology for identifying potential information voids in online conversations. JMIR Infodemiology. 2021;1 (1):e30971. doi:10.2196/30971

87. World Health Organization. 4th virtual WHO infodemic management conference: advances in social listening for public health; 2021. Available from: https://www.who.int/news-room/events/ detail/2021/05/04/default-calendar/4th-virtual-who-infodemicmanagement-conference-advances-in-social-listening-for-publichealth. Accessed July 22, 2021.

88. Harries D. 'Infodemic' - the fight against fake coronavirus news. China Global Television Network. 2020 February 7.

89. Richtel MWHO. Fights a Pandemic besides coronavirus: an 'infodemic'. The New York Times. 2020 February 6.

90. Thomas T. WHO says fake coronavirus claims causing 'infodemic'. BBC. 2020 February 20.

91. Niemiec E. COVID-19 and misinformation: is censorship of social media a remedy to the spread of medical misinformation? EMBO Rep. 2020;21(11):e51420-e51420. doi:10.15252/ embr.202051420

92. Larson HJ. Stuck: How Vaccine Rumors Start - And Why They Don't Go Away. New York, NY: Oxford University Press; 2020.

93. Eagly AH, Chaiken S. The Psychology of Attitudes. New York: Academic Press; 1993.

94. McGuire WJ. The nature of attitudes and attitude change. In: Lindzey G, Aronson E, editors. The Handbook of Social Psychology. Vol. 3. Reading, MA: Addison-Wesley; 1969:136-314.

95. Petty RE, DeSteno D, Rucker DD. The role of affect in attitude change. In: Forgas JP, editor. Handbook of Affect and Social Cognition. Mahwah, NJ: Lawrence Erlbaum Associates; 2001:212-233.

96. Biener L. Adult and youth response to the Massachusetts anti-tobacco television campaign. J Public Health Manag Pract. 2000;6(3):40-44. doi:10.1097/00124784-200006030-00007

97. Biener L, Reimer RL, Wakefield M, Szczypka G, Rigotti NA, Connolly G. Impact of smoking cessation aids and mass media among recent quitters. Am J Prev Med. 2006;30(3):217-224. doi:10.1016/j.amepre.2005.10.026

98. Dillard JP, Nabi RL. The persuasive influence of emotion in cancer prevention and detection messages. J Commun. 2006;56 (s1):S123-S139. doi:10.1111/j.1460-2466.2006.00286.x

99. Dillard JP, Peck E. Affect and persuasion: emotional responses to public service announcements. Commun Res. 2000;27 (4):461-495. doi:10.1177/009365000027004003
100. Pechmann C, Reibling ET. Antismoking advertisements for youths: an independent evaluation of health, counter-industry, and industry approaches. Am J Public Health. 2006;96 (5):906-913. doi:10.2105/AJPH.2004.057273

101. Gesser-Edelsburg A. Using narrative evidence to convey health information on social media: the case of COVID-19. J Med Internet Res. 2021;23(3):e24948. doi:10.2196/24948

102. Kreuter MW, Green MC, Cappella JN, et al. Narrative communication in cancer prevention and control: a framework to guide research and application. Ann Behav Med. 2007;33(3):221-235. doi:10.1007/BF02879904

103. Gesser-Edelsburg A. Drama as a rhetorically effective health communication strategy: risks and benefits. In: Kim DK, Singhal A, Kreps GL, editors. Global Health Communication Strategies in the 21st Century: Design, Implementation, and Evaluation. New York, NY: Peter Lang Publishing Group; 2014:134-150.

104. Green MC, Brock TC. The role of transportation in the persuasiveness of public narratives. J Pers Soc Psychol. 2000;79 (5):701-721. doi:10.1037//0022-3514.79.5.701

105. Diekman AB, Gardner WL, McDonald M. Love means never having to be carreful: the relationship between reading romance novels and safe sex behavior. Psychol Women Q. 2000;24 (2):179-188. doi:10.1111/j.1471-6402.2000.tb00199.x

106. Gesser-Edelsburg A, Singhal A. Enhancing the persuasive influence of entertainment-education events: rhetorical and aesthetic strategies for constructing narratives. Crit Arts. 2013;27 (1):56-74. doi:10.1080/02560046.2013.766973

107. Hopfer S, Clippard JR. College women's HPV vaccine decision narratives. Qual Health Res. 2011;21(2):262-277. doi:10.1177/ 1049732310383868

108. Yoshioka T, Maeda Y. COVID-19 stigma induced by local government and media reporting in Japan: it's time to reconsider risk communication lessons from the Fukushima Daiichi nuclear disaster. $J$ Epidemiol. 2020;30(8):372-373. doi:10.2188/jea. JE20200247

109. Nutbeam D. COVID-19: lessons in risk communication and public trust. Public Health Res Pract. 2020;30(2). doi:10.17061/ phrp3022006

110. Ashkenazi S. Scientists against government guidelines: there is no medical reason for the aggravation of the subject of masks. Globes. 2020 April 27.

111. Filut A. Board of the association of public health physicians: the charge to wear a mask may harm the eradication of the corona. Calcalist. 2020 April 2.

112. MacIntyre CR, Chughtai AA. Facemasks for the prevention of infection in healthcare and community settings. BMJ. 2015;350 (apr09 1):h694. doi:10.1136/bmj.h694

113. van Asselt MBA, Vos E. Wrestling with uncertain risks: EU regulation of GMOs and the uncertainty paradox. J Risk Res. 2008;11(1-2):281-300. doi:10.1080/13669870801990806

114. van Asselt MBA, Vos E, Rooijackers B. Science, knowledge and uncertainty in EU risk regulation. In: Everson M, Vos E, editors. Uncertain Risks Regulated. Oxon, OX: Routledge-Cavendish; 2009:359-388.

115. Fox T. The role of uncertainty intolerance in European risk governance. Paper presented at: Risk Research Symposium; 2009; King's College London.

116. Gesser-Edelsburg A, Hijazi R. When politics meets pandemic: how Prime Minister Netanyahu and a small team communicated health and risk information to the Israeli public during the early stages of COVID-19. Risk Manag Healthc Policy. 2020;13:2985-3002. doi:10.2147/RMHP.S280952 
117. Sandman P, Lanard J. Explaining and proclaiming uncertainty: risk communication lessons from Germany's E. coli outbreak; August 14, 2011. Available from: http://www.psandman.com/ col/GermanEcoli.htm. Accessed November 23, 2014.

118. Lofstedt RE. How can we make food risk communication better: where are we and where are we going? J Risk Res. 2006;9 (8):869-890. doi:10.1080/13669870601065585

119. Porat T, Nyrup R, Calvo RA, Paudyal P, Ford E. Public health and risk communication during COVID-19-enhancing psychological needs to promote sustainable behavior change. Front Public Health. 2020;8:573397. doi:10.3389/fpubh.2020.573397

120. Irwin A. Citizen Science: A Study of People, Expertise and Sustainable Development. London and New York: Routledge; 1995.

121. Guerrini CJ, Majumder MA, Lewellyn MJ, McGuire AL. Citizen science, public policy. Science. 2018;361(6398):134-136. doi:10.1126/science.aar8379

122. Center for Human Environments. Public Science Project (PSP). The City University of New York; 2020. Available from: https:// www.gc.cuny.edu/Page-Elements/Academics-Research-CentersInitiatives/Centers-and-Institutes/Center-for-HumanEnvironments/Research-Sub-Groups/Public-Science-Project(PSP). Accessed November 10, 2020.

123. Open Government Partnership. Civil society engagement; 2020. Available from: https://www.opengovpartnership.org/civilsociety-engagement/. Accessed November 10, 2020.

124. Motion A. It's personal. Chemistry World; 2020. Available from: https://www.chemistryworld.com/opinion/the-citizen-scientistssharing-their-own-data-during-The-covid-19-pandemic/4011793. article. Accessed November 10, 2020

125. Chesbrough HW. Open Business Models: How to Thrive in the New Innovation Landscape. Boston, MA: Harvard Business School Press; 2006.

126. Zoref L. Mindsharing: The Art of Crowdsourcing Everything. New York: Penguin Publishing Group; 2015.

127. Global Development. Crowdsourcing reveals life-saving potential in global health research. The Guardian. 2012 August 15.

128. Wiggins A, Wilbanks J. The rise of citizen science in health and biomedical research. Am J Bioeth. 2019;19(8):3-14. doi:10.1080/ 15265161.2019.1619859

129. CDC. Vaccination rates among children in kindergarten - United States, 2012-2013 school year. MMWR. 2013;62(30):607-612.

130. Gesser-Edelsburg A, Walter N, Shir-Raz Y, Sassoni Bar-Lev O, Rosenblat S. The behind-The-scenes activity of parental decision-making discourse regarding childhood vaccination. $\mathrm{Am}$ $J$ Infect Control. 2017;45(3):267-271. doi:10.1016/j. ajic.2016.10.009

131. Velan B, Boyko V, Lerner-Geva L, Ziv A, Yagar Y, Kaplan G. Individualism, acceptance and differentiation as attitude traits in the public's response to vaccination. Hum Vaccin Immunother. 2012;8(9):1272-1282. doi:10.4161/hv.21183

132. Smith RD. Responding to global infectious disease outbreaks: lessons from SARS on the role of risk perception, communication and management. Soc Sci Med. 2006;63(12):3113-3123. doi:10.1016/j.socscimed.2006.08.004

133. Kasperson RE, Renn O, Slovic P, et al. The social amplification of risk: a conceptual framework. Risk Anal. 1988;8(2):177-187. doi:10.1111/j.1539-6924.1988.tb01168.x
134. Dickson D. The Case for a 'Deficit Model' of Science Communication. SciDevNet; 2005.

135. Kreuter MW, Strecher VJ, Glassman B. One size does not fit all: the case for tailoring print materials. Ann Behav Med. 1999;21 (4):276-283. doi:10.1007/bf02895958

136. Lee NR, Kotler P. Social Marketing Influencing Behaviors for Good. 4th ed. Thousand Oaks, CA: SAGE Publications, Inc.; 2011.

137. Morgan MG, Fischhoff B, Bostrom A, Atman CJ. Risk Communication: A Mental Models Approach. New York: Cambridge University Press; 2002.

138. World Health Organization. 1st WHO infodemic manager training; 2020. Available from: https://www.who.int/teams/riskcommunication/infodemic-management/1st-who-training-in-info demic-management. Accessed August 18, 2021.

139. World Health Organization. Call for applicants for 2nd WHO training in infodemic management; 2021. Available from: https://www.who.int/news-room/articles-detail/call-for-appli cants-for-2nd-who-training-in-infodemic-management. Accessed August 18, 2021.

140. World Health Organization. Assessment Report of the Global Vaccine Action Plan. Strategic Advisory Group of Experts on Immunization. Geneva: World Health Organization; 2018.

141. Kincaid DL. The convergence model of communication. Papers of the East-West Communication Institute;no 18; 1979. Available from: https://scholarspace.manoa.hawaii.edu/handle/10125/ 48094. Accessed July 22, 2021.

142. Rogers EM, Kincaid DL. Communications Networks: Toward a New Paradigm for Research. New York: The Free Press; 1981.

143. Brooks LA, Manias E, Bloomer MJ. Culturally sensitive communication in healthcare: a concept analysis. Collegian. 2019;26 (3):383-391. doi:10.1016/j.colegn.2018.09.007

144. Thiederman S. Improving communication in a diverse healthcare environment. Healthc Financ Manage. 1996;50(11):72,74-75.

145. Dutta-Bergman MJ. Theory and practice in health communication campaigns: a critical interrogation. Health Commun. 2005;18 (2):103-122. doi:10.1207/s15327027hc1802_1

146. Dutta MJ. Communicating Health: A Culture-Centered Approach. Cambridge: Polity Press; 2013.

147. Huo J, Desai R, Hong Y-R, Turner K, Mainous AG 3rd, Bian J. Use of social media in health communication: findings from the health information national trends survey 2013, 2014, and 2017. Cancer Control. 2019;26(1):1073274819841442. doi:10.1177/ 1073274819841442

148. Beatty J. Masking disagreement among experts. Episteme. 2006;3 (1-2):52-67. doi:10.3366/epi.2006.3.1-2.52

149. Lavazza A, Farina M. The role of experts in the Covid-19 pandemic and the limits of their epistemic authority in democracy. Front Public Health. 2020;8:356. doi:10.3389/fpubh.2020.00356

150. Gesser-Edelsburg A, Zemach M, Hijazi R. Who are the "real" experts? The debate surrounding COVID-19 health risk management: an Israeli Case Study. Risk Manag Healthc Policy. 2021;14:2553-2569. doi:10.2147/RMHP.S311334 


\section{Publish your work in this journal}

Risk Management and Healthcare Policy is an international, peerreviewed, open access journal focusing on all aspects of public health, policy, and preventative measures to promote good health and improve morbidity and mortality in the population. The journal welcomes submitted papers covering original research, basic science, clinical \& epidemiological studies, reviews and evaluations, guidelines, expert opinion and commentary, case reports and extended reports. The manuscript management system is completely online and includes a very quick and fair peer-review system, which is all easy to use. Visit http://www.dovepress.com/testimonials.php to read real quotes from published authors.

Submit your manuscript here: https://www.dovepress.com/risk-management-and-healthcare-policy-journal 